\title{
The microcosm of particles within seagrass Posidonia oceanica canopies
}

\author{
Carlos M. Duarte*, Esther Benavent, Maria del Carmen Sánchez \\ Instituto Mediterráneo De Estudros Avanzados (IMEDEA), CSIC-UIB, c/ Miquel Marqués 21, E-07190 Esporles, Mallorca \\ (Islas Baleares), Spain
}

\begin{abstract}
Comparison of the amount and nature of suspended material within Posidonia oceanica canopies, in 6 meadows in the Spanish Mediterranean coast differing in extent and depth, with those in the overlying waters showed the canopies to be significantly enriched in particulate organic carbon, nitrogen and phosphorus relative to the overlying waters (on average, 87,34 and $54 \%$ more $\mathrm{C}, \mathrm{N}$ and $P$, respectively). Biovolume of detritus (both angiosperm-derived and plankton-derived) was large, particularly within seagrass canopies, where it dominated the seston pool (about 5-fold greater biovolume than that of living particles), compared to a roughly equal biovolume of detrital and living particles in the particle pools in the overlying waters. The dominance of detrital particles was further reflected in the high $\mathrm{C} / \mathrm{N}$ and $\mathrm{C} / \mathrm{P}$ ratios of the suspended materials (median atomic $\mathrm{C}: \mathrm{N}: \mathrm{P}$ ratios $=492: 40.9: 1$ and 596:45:1 of the materials suspended within the canopy and in the overlying waters, respectively), which were intermediate between those of living plankton and $P$. oceanica. The relative enrichment of $P$. oceanica canopies by particles tended to be greatest when particle loads in the overlying waters were small, suggesting that the effect of seagrasses as traps of particles is enhanced in particle-poor waters. The results obtained support the hypothesis that the water within seagrass canopies is enriched by (mostly detrital) particles, particularly in particle-poor waters. This suggests that seagrasses not only contribute a substantial fraction of the particles themselves, but also act as sinks of particles.
\end{abstract}

KEY WORDS: Seagrass · Seston · Sedimentation · Detritus

\section{INTRODUCTION}

Current dogma assumes that seagrass meadows trap sediments, thereby enhancing rates of sedimentation (e.g. Ginsburg \& Lowenstam 1959, Scoffin 1970, Ward et al. 1984, Almansi et al. 1987). The direct empirical information available to support this belief is, however, limited (e.g. Ward et al. 1984, Almansi et al. 1987). The notion that seagrass canopies trap particles suggests that, in the absence of resuspension, they should be enriched in particles relative to the overlying waters. Yet, the few data available are either inconclusive (Judge et al. 1993) or opposite (Ward et al. 1984) to this expectation. Even such a finding would not be sufficient evidence for seagrasses trapping particles from the overlying waters. The reason for this is that sea-

\footnotetext{
- Address for correspondence: Centro de Estudios Avanzados de Blanes, CSIC, Cami de Santa Barbara s/n, E-17300 Blanes, Spain. E-mail: duarte@ceab.csic.es
}

grasses may produce a large number of particles themselves, either as detrital particles detached from senescent leaves or as organisms growing on carbon derived from seagrasses. Seagrass meadows rank amongst the most productive communities on Earth (Duarte \& Chiscano 1999), a production that, because of the generally minor role of grazers, is largely used by detritivores (cf. Cebrián \& Duarte 1994, Duarte \& Cebrián 1996). Moreover, seagrass leaves support large biomasses of epiphytes, which can also generate particles (both detrital and living). Hence, seagrass canopies are expected to be sources of particles.

The elucidation of the role of seagrasses in sedimentary processes in shallow coastal ecosystems requires knowledge of the balance between their role in trapping particles from the overlying water column (i.e. particle sinks) and their production (i.e. particle sources) and retention of particles. Because of the relatively quiescent environment within seagrass canopies (cf. Fonseca et al. 1982, Gambi et al. 1990, Fonseca \& 
Calahan 1992, Ackerman \& Okubo 1993), both processes would promote sedimentation, and enhance the role of seagrasses in the sedimentary dynamics of coastal ecosystems.

We examine here the abundance and nature of the particles suspended within and above seagrass canopies, to test the hypotheses that seagrass canopies are enriched in particles relative to the overlying waters, and that seagrasses contribute a significant fraction of the particles themselves. We surveyed the particle pools in meadows of the Mediterranean seagrass Posidonia oceanica differing in extent and depth. We compared the nature and mass of the particle pool within the plant canopies and those in the overlying waters. In order to provide a thorough characterisation of the particles present in the seston, we combined a number of techniques to identify the nature of the diversity of particles present and, therefore, their likely sources.

\section{METHODS}

We sampled 6 meadows of Posidonia oceanica located on the northeast (2 patchy meadows, Giverola Cove and Fenals Point) and southeast (4 large meadows, Aguamarga, sampled at 3 and $20 \mathrm{~m}$ depth, Rodalquilar, Carboneras, and Villaricos) Spanish Mediterranean coast. General characteristics of these meadows can be found in Cebrián et al. (1996) and Marbá et al. (1996). The southeast meadows were visited between mid June and mid September 1996, the time of greatest canopy development (cf. Alcoverro et al. 1995). The northeast meadows, located closer to our laboratory, were visited 4 times to provide an indication of the variability of the size and nature of the particle pool. The first sampling event included only estimates of particulate carbon, nitrogen and phosphorus.

At each site, water samples were collected by SCUBA divers from within the canopy and about $0.5 \mathrm{~m}$ above the canopy using between 3 and 6 replicated corers (58 cm long and $6.5 \mathrm{~cm}$ in internal diameter). The corers to sample the waters within the canopy were carefully moved in between the leaves to enclose a volume of water without disturbing the seagrass leaves, which would likely release particles, also avoiding bubbling or turbulence which could lead to coagulation of particles. We also measured the height of the canopy, at 6 points within the location where the corers were collected, at each location sampled. Shoot density was measured by counting the shoots within 4 randomly placed $50 \times 50 \mathrm{~cm}$ quadrats, and 15 shoots were randomly collected, dried (overnight at $80^{\circ} \mathrm{C}$ ) and weighed to determine shoot biomass wherever this was not already available.
Total mass of seston and the particulate organic carbon, nitrogen and phosphorus content of the seston were measured at the laboratory. Particulate organic carbon, nitrogen and phosphorus were measured, in duplicate, from the particles collected after filtering 200 to $400 \mathrm{ml}$ of sampled water on Whatman GF/F filters. Before use, the filters utilized for the $\mathrm{C}$ and $\mathrm{N}$ analysis were combusted; those used for $\mathrm{P}$ analyses were acid-washed ( $\mathrm{HCl} 10 \%)$. The samples were kept frozen until analysis. Particulate organic carbon and nitrogen were measured using a Carlo Erba CHN analyzer (model 1104), after removing inorganic carbon with $\mathrm{HCl}$ fumes. Particulate phosphorus was determined as soluble reactive $\mathrm{P}$ (SRP) after oxidation of the sample in acidic persulfate at $120^{\circ} \mathrm{C}$ for $30 \mathrm{~min}$ (Koroleff 1983). After oxidation, the sample was filtered through a Whatman GF/F filter to remove turbidity.

The abundance and biovolume of different types of particles were estimated using an epifluorescence microscope, after staining the particles retained in different filters (Fig. 1) with different fluorochromes to trace different types of particles. We used different particles and concentration procedures (filtered volumes: $15 \mathrm{ml}$ for the smallest particles to $500 \mathrm{ml}$ for the largest ones) to cope with the broad size spectrum of the particles $(<1$ to $200 \mu \mathrm{m})$. Living particles were classified as either heterotrophs or autotrophs depending on whether they contained DNA (i.e. positive to DAPI, Fig. 1) and chlorophyll a (positive both to DAPI and autofluorescence excitation of chlorophyll a with blue light, Fig.1). Cyanobacteria were differentiated by their orange color when stimulated with blue light derived from their phycocyanin (Fig. 1). Organic detritus was estimated as the particles positively stained with the vital stain propidium iodide (PI, Fig. 1), as described by Williams et al. (1995). Detritus of angiosperms was identified as those particles that fluoresced in greenyellow after staining with calcofluor white (CW, Fig. 1), a fluorochrome specific for cellulose (Williams et al. 1995). That Posidonia oceanica detritus is stained with CW was confirmed by microscopic examination of a sample of dried, powdered (using an agate mortar) $P$. oceanica leaves. Seagrasses, however, are not the only sources of cellulose-containing particles in the sea, for dinoflagellates often have cellulose plates (Taylor 1987), and particles washed from terrestrial vegetation should also contain cellulose. Dinoflagellates were readily discriminated from detritus because of their geometric and uniform shape, whereas detritus was always amorphous. In addition to cellulose-containing particles, we consistently observed bright white-fluorescent particles in filters examined under UV light. These were found to be inorganic particles, as confirmed by the presence of these particles after combustion of seston at $400^{\circ} \mathrm{C}$ for $4 \mathrm{~h}$. 


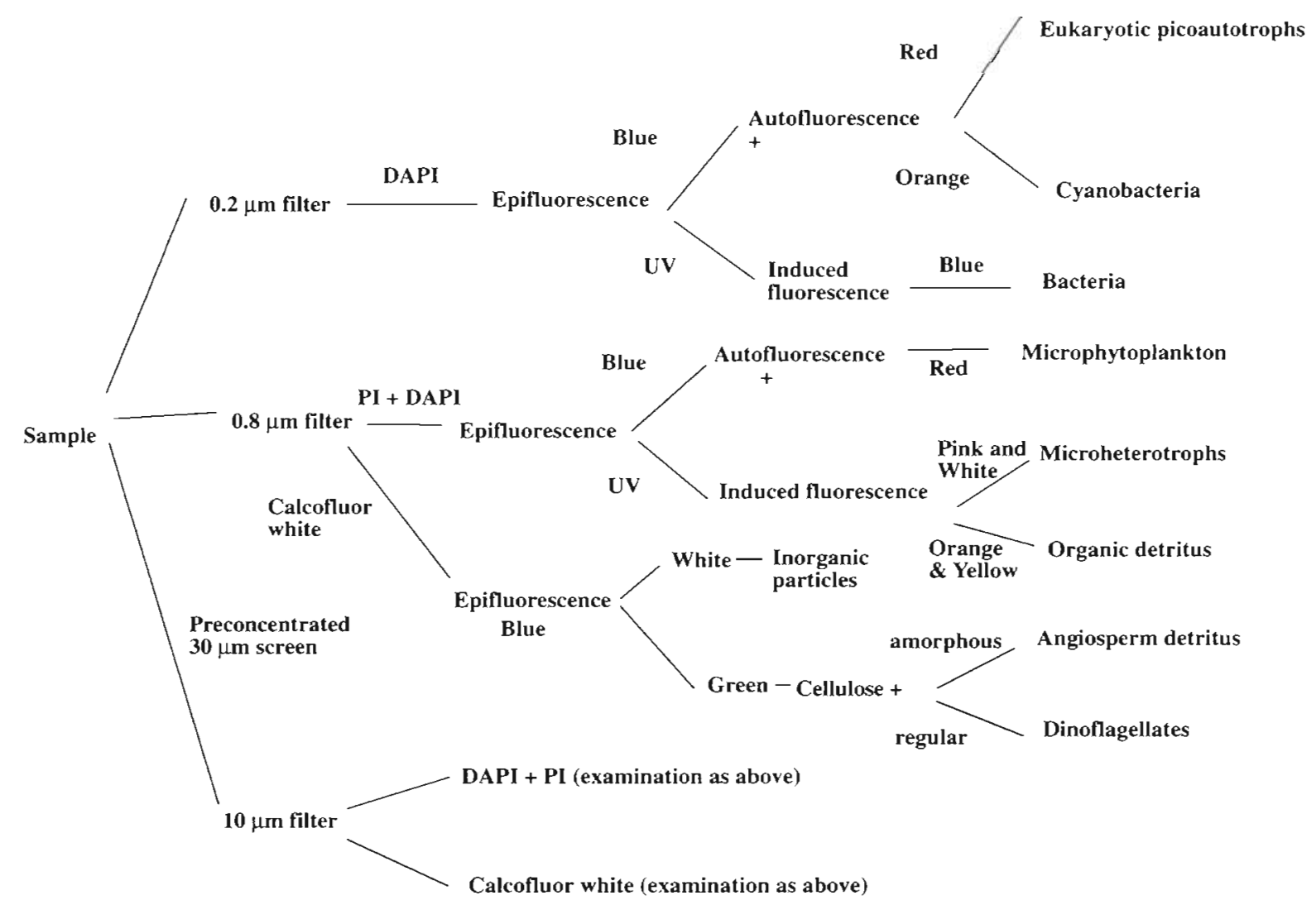

Fig. 1. Summary of the techniques used in the microscopic examination of particles within Posidonia oceanica canopies and the overlying waters. PI: propidium iodide. +: positive staining with the fluorochrome tested

The abundance of particles was counted under a Zeiss Axioplan epifluorescence microscope, fitted with a blue and UV filter and examined at 200,400 or $1000 \times$ magnification, depending on the size of particles. The abundance of particles was assessed by counting enough fields to contain at least 200 particles or those within 40 microscope fields of each type. The largest dimension of each of these particles was estimated using a micrometer fitted onto the eye-piece of the microscope and the second major axis (perpendicular to the largest dimension) was estimated in a subset of the particles. The allometric relationship between the 2 characteristic dimensions of the particles (allometric exponents ranging between 0.74 and 1.47, depending on the particle type) was then used to estimate, by approximation to the nearest geometric shape, the volume of each of the particles from measurements of their largest dimension.

The replicated samples were averaged to provide an average description of the conditions at the time of sampling. The coefficients of variation were $<20 \%$ for elemental concentrations, and $<60 \%$ for microscopically derived particle abundance, being, therefore, small compared to the range of the average values obtained. Different visits to the same meadow were used as independent samples, since analyses for the meadows sampled 3 times showed temporal changes in the loads of particles over the grasses to be a significant source of variance, together with variance among meadows. Hence, the analysis was based on 13 data points for particle load, and 11 data points for data derived from microscopic determinations.

\section{RESULTS}

Posidonia oceanica canopies ranged between 30 and $66 \mathrm{~cm}$ in height, with an average of $48 \mathrm{~cm}$. Shoot density and leaf biomass ranged from 104 to 683 shoots $\mathrm{m}^{-2}$ and 117 to $700 \mathrm{~g} \mathrm{DW} \mathrm{m}^{-2}$, respectively. We found the waters within the $P$. oceanica canopy to be significantly (Wilcoxon ranked sign test, $p=0.002$ ) enriched in particles relative to the overlying waters, as demonstrated by the observation that the waters within the canopy contained, on average, $87 \%$ more POC than the overlying waters (Fig. 2). The particulate organic nitrogen and phosphorus in the waters within the plant canopies were also significantly enriched in N and P (34 and $54 \%$ higher, Wilcoxon ranked sign test, $\mathrm{p}=0.003$ 

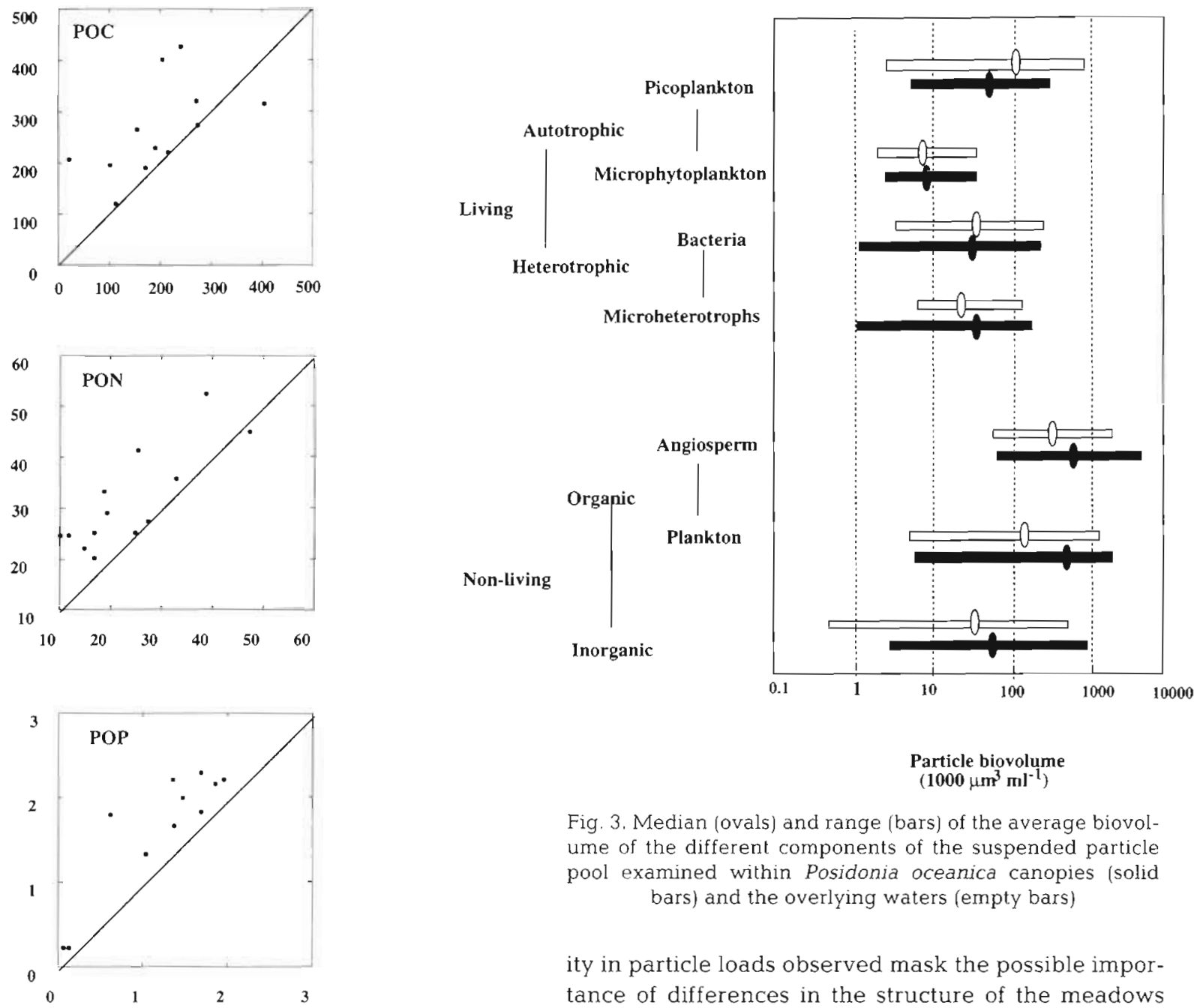

Particle biovolume
$\left(1000 \mu \mathrm{m}^{3} \mathrm{ml}^{-1}\right)$

Fig. 3. Median (ovals) and range (bars) of the average biovolume of the different components of the suspended particle pool examined within Posidonia oceanica canopies (solid bars) and the overlying waters (empty bars)

ity in particle loads observed mask the possible importance of differences in the structure of the meadows (shoot density and biomass).

Elemental concentration in overlying waters $(\mu \mathrm{g} / \mathrm{L})$

Fig. 2. Relationship between particulate organic carbon, nitrogen and phosphorus (POC, PON and POP, respectively) concentrations within Posidonia oceanica canopies and those

in the overlying waters. Solid lines represent $1: 1$ lines

and $p=0.006$, respectively) relative to the overlying waters (Fig. 2). The sestonic material was relatively depleted in $\mathrm{N}$ and $\mathrm{P}$ relative to $\mathrm{C}$ (median atomic $C: N: P$ ratios $=492: 41: 1$ and $596: 45: 1$ for the materials suspended within the canopy and in the overlying waters, respectively). They did not differ significantly between the materials suspended within the canopy and in the overlying waters $(p>0.05)$, although there was a tendency for the particles suspended in the overlying particles to be more depleted in $\mathrm{P}$ relative to $\mathrm{C}$ than those within the canopy. Variation in time was an important source of variance (ANOVA, F-test, p < 0.001), indicating that the processes (physical forcing, plankton dynamics, etc.) that induce the high variabil-

Living plankton was dominated by picoplankton $(<3 \mu \mathrm{m})$ in the autotrophic community, where Synechococcus sp. comprised most of the biovolume, and in the heterotrophic community, where bacteria represented about $50 \%$ of the total biovolume (Fig. 3). Microheterotrophs, largely ciliates, comprised a greater share of the biomass of heterotrophs than did microphytoplankton for autotrophs (Fig. 3). The biovolume of autotrophs tended to exceed that of heterotrophs (Fig. 4), the difference being larger, albeit not significantly so ( $t$-test, $p>0.05$ ), within plant canopies than above them (median planktonic heterotroph/autotroph biovolume $=0.73$ and 0.91 , respectively). The biovolume of detritus was quite large, organic detritus exceeding, by volume, that of inorganic particles, although waters bearing large concentrations of organic detritus also tended to bear large loads of inorganic particles (Fig. 5). The biovolumes of seagrassderived and plankton-derived detritus were both quite high, with particles derived from seagrasses consistently showing high biovolumes (Fig. 3). 
Most of the differences in the observed biovolume of particles were attributable to differences among locations and sampling times (on average about $60 \%$ of the variance in particle biovolume), whereas differences between loads of particles within seagrass canopies and in the overlying waters were comparatively small. Waters collected within seagrass canopies tended to support significantly greater loads of detritus than those collected in the overlying open waters (Fig. 6). This difference was somewhat larger for the volume of plankton-derived detritus than that for detritus derived from angiosperms (Fig. 6). As a consequence, the total volume of particles within seagrass canopies tended to be dominated by detritus, while living particles represented only $27 \%$ of the biovolume of detritus, compared to a roughly equal biovolume of detrital and living particles in the particle pools of the overlying waters (ratio of detrital to living biovolume $=0.85$, Fig. 4). There was a significant tendency ( $p<0.0001)$ for plant canopies in waters with small loads of particles to be enriched in autotrophs and detritus relative to the particle-poor overlying waters. This resulted in a tendency for the relationships between the load of particles within seagrass canopies and those in the overlying waters to be non-linear (Fig. 6). The particle load within the canopies increased proportionally to the square root of that in the overlying waters (slopes of the log-log relationships: autotrophs $=0.51 \pm 0.14\left[R^{2}=0.53\right.$, $p<0.01]$, detritus $=0.58 \pm 0.23\left[R^{2}=0.32, p<0.05\right]$, seagrass detritus $=0.58 \pm 0.33\left[R^{2}=0.22, p>0.05\right)$, inorganic particles $=0.58 \pm 0.15\left[\mathrm{R}^{2}=0.56, \mathrm{p}<0.005\right]$, heterotrophs $\left.=1.03 \pm 0.25\left[\mathrm{R}^{2}=0.60, \mathrm{p}<0.005\right]\right)$.

\section{DISCUSSION}

Seagrass canopies were enriched in sestonic materials relative to the overlying waters, resulting in greater (30 to $80 \%$ ) loads of particulate carbon, nitrogen and phosphorus in the sestonic material. These findings are consistent with earlier reports of increased loads of seston within seagrass canopies derived using siphon mimics of filter feeders (e.g. Judge et al. 1993), and help explain the reported enhanced growth rates of filter feeding organisms within seagrass canopies (Peterson et al. 1984, Irlandi \& Peterson 1991).

The living planktonic community was characterised by a dominance of cyanobacteria among the autotrophs, as expected for summer Mediterranean plankton (Mura et al. 1996), indicative of a food web dominated by microbial interactions. Living organisms contribute, on average, an equal biovolume to the seston pool in the waters overlying the seagrass canopies as that of detritus, whereas detritus represents, on average, 4-fold more biovolume than that of living organisms within the sea-
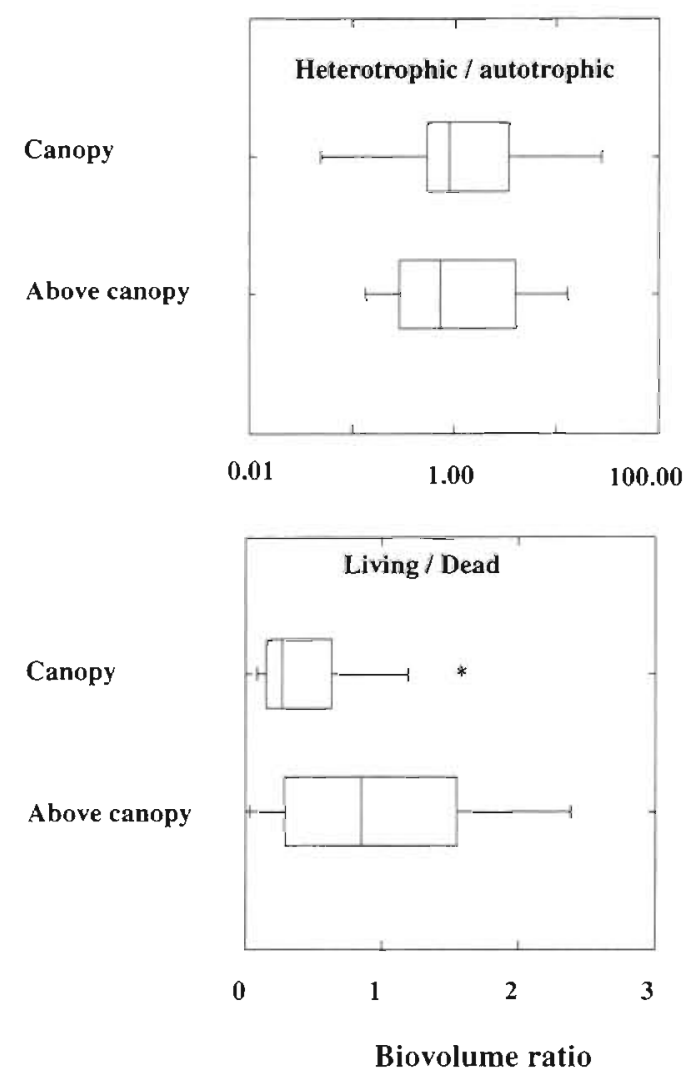

Fig. 4. Box plots showing the distribution of the ratios of the biovolume of microautotrophs to that of microheterotrophs and that between living and dead particles within Posidonia oceanica canopies and the overlying waters. Boxes encompass $50 \%$ of the values, the line represents the median value, and the bars extend to the $95 \%$ confidence limits

grass canopy. This was true, however, of the biovolumes of both detritus derived from angiosperms, detritus derived from plankton, and inorganic detritus. The fact that the microcosm of particles within Posidonia oceanica

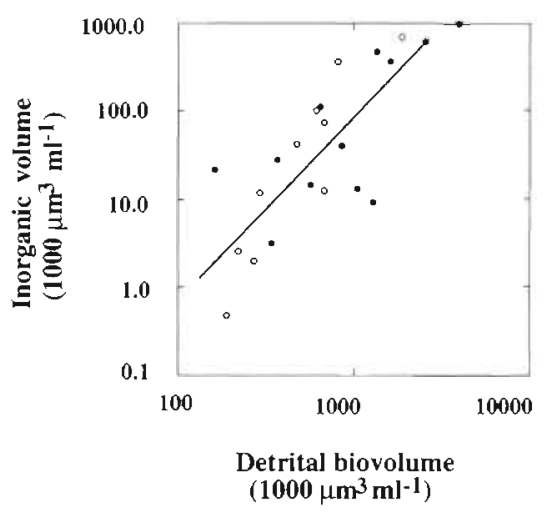

Fig. 5. Relationship between the volume of inorganic particles and that of organic detritus within Posidonia oceanica canopies $(\bullet)$ and the overlying waters $(0)$ 

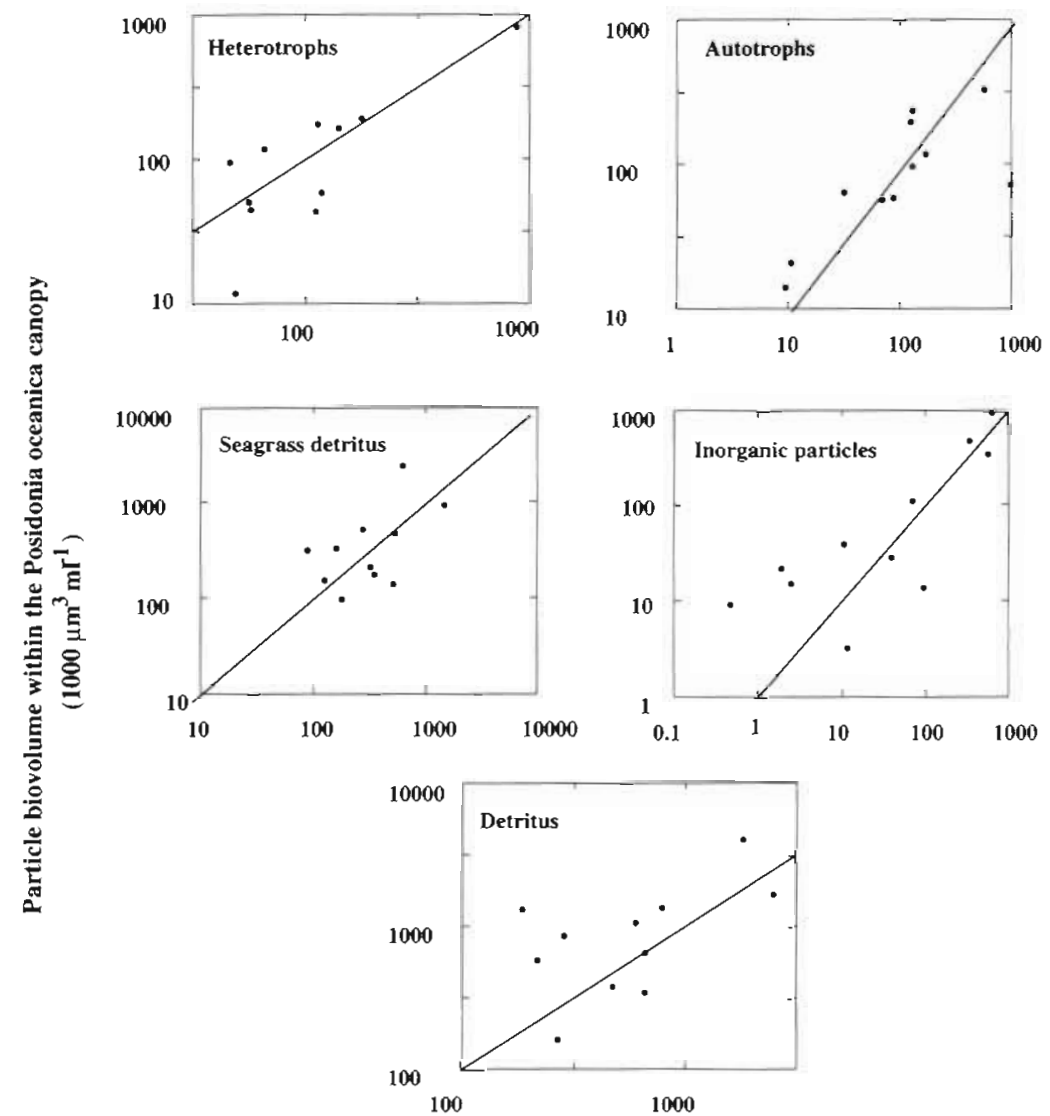

Particle biovolume above the Posidonia oceanica canopy $\left(1000 \mu \mathrm{m}^{3} \mathrm{ml}^{1}\right)$

Fig. 6. Relationship between the biovolume of different components of the suspended particle pool within Posidonia oceanica canopies and that in the overlying waters. Solid lines represent 1:1 line the overlying waters were small. This suggests that the effect of seagrasses as traps of particles, either produced locally or trapped by their canopies, tends to be enhanced in particle-poor waters, probably because this effect is relatively small and only becomes significant in particlepoor waters. The fact that substantial loads of angiosperm-derived detritus were also found, albeit in lower amounts, in the overlying waters suggests that seagrasses also export detrital particles, acting, therefore, both as sources and sinks of particles.

The results described support the hypothesis that the water within seagrass canopies is enriched in (mostly detrital) particles, particularly in particle-poor waters, and suggests that seagrasses themselves contribute a substantial fraction of the particles. The results obtained support the view that seagrass canopies act both as particle sinks and as particle sources. The procedures used demonstrate a novel approach to examine the nature of the microcosm of particles suspended in seawater, which allows inferences on the likely sources of these particles. These results highlight the need to examine the balance between the production and trapping or export of particles within seagrass canopies in order to elucidate the role of seagrass meadows in the sedimentary fluxes of vegetated coastal zones. canopies was dominated by detrital particles is consistent with the observation that most of the production of seagrasses is channeled through the detrital food web (Duarte \& Cebrián 1996), and that grazing on $P$. oceanica leaves removes only a marginal fraction of its production (about $2 \%$ on average, Cebrián et al. 1996) The dominance of detrital particles was further reflected in the high $\mathrm{C} / \mathrm{N}$ and $\mathrm{C} / \mathrm{P}$ ratios of the suspended materials, which were intermediate between those of living plankton and $P$. oceanica (cf. Alcoverro et al. 1995).

Whether the planktonic organisms and inorganic detritus observed within the seagrass canopy were produced locally or settled from the overlying plankton could not be established here, although the general correlation between these components of the microcosm of particles suggests a common source. We observed, however, that seagrass canopies were enriched in particulate organic carbon, largely composed of detrital particles and autotrophic plankton. This effect appeared to be greatest whenever loads of particles in
Acknowledgements. This work is a contribution to the project MAS3-CT96-0053 of the ELOISE programme, funded by MAST III (CE). We thank Tim Granata, Hilary Kennedy, Sarah Proud, and Paul Kennedy for assistance in the field.

\section{LITERATURE CITED}

Ackerman JD, Okubo A (1993) Reduced mixing in a marine macrophyte canopy. Funct Ecol 7: 305-309

Alcoverro T, Duarte CM, Romero J (1995) Annual growth dynamics of Posidonia oceanica: contribution of largescale versus local factors to seasonality. Mar Ecol Prog Ser $120: 203-210$

Almasi MN, Hoskin CM, Reed JK, Milo J (1987) Effects of natural and artificial Thalassia on rates of sedimentation. J Sediment Petrol 57:901-906

Cebrián J, Duarte CM (1994) The dependence of herbivory on growth rate in natural plant communities. Funct Ecol 8: $518-525$

Cebrián J, Duarte CM, Marbá N, Enríquez S, Gallegos ME, Olesen B (1996) Hervibory on Posidonia oceanica: magnitude and variability in the Spanish Mediterranean. Mar Ecol Prog Ser 130:147-155 
Duarte CM, Cebrián J (1996) The fate of marine autotrophic production. Limnol Oceanogr 41:1758-1766

Duarte CM, Chiscano CL (1999) Seagrass biomass and production: a reassessment. Aquat Bot (in press)

Fonseca MS, Calahan JA (1992) A preliminary evaluation of wave attenuation by four species of seagrass. Estuar Coast Shelf Sci 35:565-576

Fonseça MS, Fisher JS, Zieman JC, Thayer GW (1982) Influence of the seagrass, Zostera marina L., on current flow. Estuar Coast Shelf Sci 15:351-364

Gambi MC, Nowell AR, Jumars PA (1990) Flume observations on flow dynamics in Zostera marina (eelgrass) beds. Mar Ecol Prog Ser 61:159-169

Ginsburg RN, Lowenstam HA (1958) The influence of marine bottom communities on depositional environment of sediments. J Geol 66:310-318

Irlandi EA, Peterson CH (1991) Modification of animal habitat by large plants: mechanisms by which seagrasses influence clam growth. Oecologia 87:307-318

Judge ML, Coen LD, Heck KL Jr (1993) Does Mercenaria mercenaria encounter elevated food levels in seagrass beds? Results from a novel technique to collect suspended food resources. Mar Ecol Prog Ser 92:141-150

Koroleff F (1983) Determination of phosphorus. In: Grasshoff K, Ehrhardt M, Kremling K (eds) Methads of seawater analysis, 2nd edn. Verlag Chemie, Weinheim, p 125-139

Editorial responsibility: Otto Kinne (Editor),

Oldendorf/Luhe, Germany
Marbá N, Duarte CM, Cebrián J, Enríquez S, Gallegos ME, Olesen B, Sand-Jensen K (1996) Growth and population dynamics of Posidonia oceanica on the Spanish Mediterranean coast: elucidating seagrass decline. Mar Ecol Prog Ser 137:203-213

Mura MP, Agustí S, Cebrián J, Satta MP (1996) Seasonal variability of phytoplankton biomass and community composition in Blanes Bay (1992-1994). Publnes Espec Inst Esp Oceanogr 22:23-29

Peterson CH, Surnmerson HC, Duncan PB (1984) The influence of seagrass cover on population structure and individual growth rate of a suspension-feeding bivalve. J Mar Res 42:123-138

Scoffin TP (1970) The trapping and binding of subtidal carbonate sediments by marine vegetation in Bimini Lagoon, Bahamas. J Sediment Petrol 40:249-273

Taylor FJR (1987) Dinoflagellate morphology. In: Taylor FJR (ed) The biology of dinoflagellates. Blackwell Sci Publ, London, p 24-91

Ward LG, Boynton WR, Kemp WM (1984) The influence of waves and seagrass communities on suspended particulates in an estuarine embayment. Mar Geol 59: $85-103$

Williams SC, Verity PG, Beatty T (1995) A new staining technique for dual identification of plankton and detritus in seawater. J Plankton Res 17:2037-2047

Submitted: June 15, 1998; Accepted: December 7, 1998

Proofs received from author(s): April 27, 1999 